\title{
The urate-lowering efficacy and safety of febuxostat in the treatment of the hyperuricemia of gout: the CONFIRMS trial
}

\author{
Michael A Becker*1, H Ralph Schumacher2 , Luis R Espinoza ${ }^{3}$, Alvin F Wells ${ }^{4}$, Patricia MacDonald55, Eric Lloyd5 and \\ Christopher Lademacher ${ }^{6}$
}

\begin{abstract}
Introduction: The purpose of this study was to compare urate-lowering (UL) efficacy and safety of daily febuxostat and allopurinol in subjects with gout and serum urate $(\mathrm{s} \cup A) \geq 8.0 \mathrm{mg} / \mathrm{dL}$ in a six-month trial.

Methods: Subjects $(n=2,269)$ were randomized to febuxostat $40 \mathrm{mg}$ or $80 \mathrm{mg}$, or allopurinol $300 \mathrm{mg}$ (200 $\mathrm{mg}$ in moderate renal impairment). Endpoints included the proportion of all subjects with sUA $<6.0 \mathrm{mg} / \mathrm{dL}$ and the proportion of subjects with mild/moderate renal impairment and sUA $<6.0 \mathrm{mg} / \mathrm{dL}$. Safety assessments included blinded adjudication of each cardiovascular (CV) adverse event (AE) and death.

Results: Comorbidities included: renal impairment (65\%); obesity (64\%); hyperlipidemia (42\%); and hypertension (53\%). In febuxostat $40 \mathrm{mg}$, febuxostat $80 \mathrm{mg}$, and allopurinol groups, primary endpoint was achieved in 45\%, 67\%, and $42 \%$, respectively. Febuxostat $40 \mathrm{mg} U \mathrm{~L}$ was statistically non-inferior to allopurinol, but febuxostat $80 \mathrm{mg}$ was superior to both $(P<0.001)$. Achievement of target s $\cup A$ in subjects with renal impairment was also superior with febuxostat 80 $\mathrm{mg}(72 \% ; P<0.001)$ compared with febuxostat $40 \mathrm{mg}(50 \%)$ or allopurinol (42\%), but febuxostat $40 \mathrm{mg}$ showed greater efficacy than allopurinol $(P=0.021)$. Rates of AEs did not differ across treatment groups. Adjudicated (APTC) CV event rates were $0.0 \%$ for febuxostat $40 \mathrm{mg}$ and $0.4 \%$ for both febuxostat $80 \mathrm{mg}$ and allopurinol. One death occurred in each febuxostat group and three in the allopurinol group.
\end{abstract}

Conclusions: Urate-lowering efficacy of febuxostat $80 \mathrm{mg}$ exceeded that of febuxostat $40 \mathrm{mg}$ and allopurinol (300/200 $\mathrm{mg}$ ), which were comparable. In subjects with mild/moderate renal impairment, both febuxostat doses were more efficacious than allopurinol and equally safe. At the doses tested, safety of febuxostat and allopurinol was comparable.

Clinical Trial Registration: NCT00430248

\section{Introduction}

Gout is an increasingly common disorder [1-5] characterized by hyperuricemia (serum urate concentration (sUA) exceeding $6.8 \mathrm{mg} / \mathrm{dL}$, the limit of urate solubility) and by acute and chronic consequences of urate crystal deposition: episodic gout flares, deforming gouty arthropathy, tophi, and urolithiasis [6]. Long-term management of recurrent or progressive gout focuses on urate-lowering therapy (ULT) aimed at maintaining sUA in a sub-saturating range, often chosen as $<6.0 \mathrm{mg} / \mathrm{dL}$ [7-12]. Achieve-

* Correspondence: mbecker@medicine.bsd.uchicago.edu

1 The University of Chicago Pritzker School of Medicine, MC0930, University of Chicago Medical Center, 5841 S. Maryland Avenue, Chicago, IL 60637, USA Full list of author information is available at the end of the article ment of this goal results in eventual cessation (and even reversal) of urate crystal deposition and clinical signs and symptoms $[8-11,13,14]$. Pharmacological approaches to ULT have, for over 40 years, involved either enhancement of renal uric acid excretion with a uricosuric, such as probenecid, or inhibition of urate production with the purine base analogue allopurinol, a xanthine oxidase (XO) inhibitor. In the United States, over 90\% of ULT prescriptions are for allopurinol, approved at doses up to 800 $\mathrm{mg}$ daily but rarely ( $<5 \%$ of patients) prescribed at doses exceeding $300 \mathrm{mg}$ daily $[15,16]$.

Several recent publications [7-11,16-18] have documented poor urate-lowering (UL) efficacy and/or clinical outcomes in gout patients, including progression to gout- 
related disability and impaired quality of life [7,19-21]. Gout patients also have high incidences of major comorbidities that may be associated with hyperuricemia or gout or both [22]. Thus, gout patients not only suffer potentially disabling and deforming arthritic disease, but are also at high risk for cardiovascular (CV) [23-29] and metabolic disorders $[29,30]$.

Febuxostat, a non-purine analogue XO inhibitor [31], has recently received regulatory approval in the United States for treatment of hyperuricemia in gout patients [32]. Three published randomized controlled trials (RCTs) in subjects with gout and baseline sUA $\geq 8.0 \mathrm{mg} /$ dL [33-35] have established superior UL efficacy (proportion of subjects achieving sUA $<6.0 \mathrm{mg} / \mathrm{dL}$ ) for febuxostat (in daily doses from 80 to $240 \mathrm{mg}$ ) compared with placebo $[33,35]$ or with allopurinol $300 \mathrm{mg}$ daily $[34,35]$. Overall rates of adverse events (AEs) were similar across treatment groups in these studies [33-35], but CV disorders, although uncommon, occurred numerically more often in febuxostat- than allopurinol-treated. Subjects who experienced these events had a prior history of $\mathrm{CV}$ disease (CVD) and/or underlying CV risk factors. This imbalance was not statistically significant or explained by known actions of febuxostat but warranted further study.

Here we report results of the CONFIRMS trial, a Phase 3 , double-blind RCT further examining the comparative UL efficacy and safety of febuxostat and allopurinol in a greater number of gout subjects than the total participating in prior comparative trials $[34,35]$. The three-fold objectives of this study were: 1) to compare the UL efficacy of febuxostat at a dose of $40 \mathrm{mg}$ with that of allopurinol at doses most commonly utilized in clinical practice; 2) to evaluate UL efficacies of $80 \mathrm{mg}$ and $40 \mathrm{mg}$ daily doses of febuxostat compared with that of allopurinol in subjects with mild or moderate renal impairment; and 3) to gain prospective, uniformly reviewed information regarding the safety of these agents, particularly their comparative CV safety.

\section{Materials and methods}

\section{Subjects, study design, and procedures}

Subjects aged 18 to 85 years with a diagnosis of gout fulfilling American Rheumatology Association preliminary criteria [36] and sUA $\geq 8.0 \mathrm{mg} / \mathrm{dL}$ were eligible for enrollment. Subjects were enrolled at 324 sites in the United States. Institutional Review Board approval was obtained, and all subjects provided written informed consent and Health Insurance Portability and Accountability Act authorization prior to any study-related procedure. At least $35 \%$ of subjects enrolled were to have mild or moderate renal impairment, defined as baseline estimated creatinine clearance (eCLcr) of 60 to $89 \mathrm{ml} /$ minutes or 30 to $59 \mathrm{ml} /$ minutes, respectively, calculated by the Cockcroft-Gault formula corrected for ideal body weight
$[37,38]$. Subjects successfully completing either of two previously reported long-term, open-label febuxostat [13] or febuxostat/allopurinol [14] extension studies were also eligible for enrollment.

Exclusion criteria included: secondary hyperuricemia (for example, due to myeloproliferative disorder); xanthinuria; severe renal impairment (eCLcr $<30 \mathrm{ml} /$ minutes $[37,38]$ ); alanine aminotransferase and aspartate aminotransferase values $>1.5$ times the upper limit of normal; consumption of more than 14 alcoholic drinks per week or a history of alcoholism or drug abuse within five years; or a medical condition that, in the investigator's opinion, would interfere with treatment, safety, or adherence to the protocol.

Subject screening evaluations included: physical examination and vital signs; medical history, a pre-specified CV history/risk form; laboratory tests (sUA, complete chemistry panel, hematology, urinalysis, and, for women, pregnancy test); echocardiogram; assessment for tophi and gout flare; and concomitant medication use. With the exception of tophus assessment, these elements, along with compliance, were repeated at bimonthly visits during the six-month treatment period. sUA was blinded after baseline determination at Day 4.

An Interactive Voice Response System was utilized by site personnel during screening visits to initiate doubleblind randomization. Subjects were randomized 1:1:1 on Day 1 to receive daily febuxostat $40 \mathrm{mg}$, febuxostat $80 \mathrm{mg}$, or allopurinol (Apotex; Weston, FL, USA). Randomization was stratified by baseline renal function and prior completion of either of two open-label extension trials $[13,14]$. Among subjects randomized to allopurinol, those with normal renal function or mild renal impairment received $300 \mathrm{mg}$ daily, and those with moderate renal impairment received $200 \mathrm{mg}$.

During a 30-day washout period for subjects receiving prior ULT, and throughout the subsequent six-month treatment period for all subjects, prophylaxis for gout flares was given either as colchicine, $0.6 \mathrm{mg}$ daily (WestWard Pharmaceutical Corporation, Eatontown, NJ, USA) or naproxen, $250 \mathrm{mg}$ twice daily (West-Ward Pharmaceutical Corporation). All subjects receiving naproxen prophylaxis also received lansoprazole $15 \mathrm{mg}$ daily (Takeda Global Research \& Development Center, Inc., Deerfield, IL, USA). Choice of prophylaxis regimen was made by the investigator and subject, taking into account prior drug tolerance and prophylaxis experience. In addition, subjects with eCLcr $<50 \mathrm{ml} /$ minute were not to receive naproxen. Gout flares were regarded as expected gout manifestations rather than as AEs.

\section{Efficacy analyses}

While 2,269 subjects were randomized to receive at least one dose of febuxostat $40 \mathrm{mg}$, febuxostat $80 \mathrm{mg}$, or allopurinol (Figure 1), one subject randomized to the 


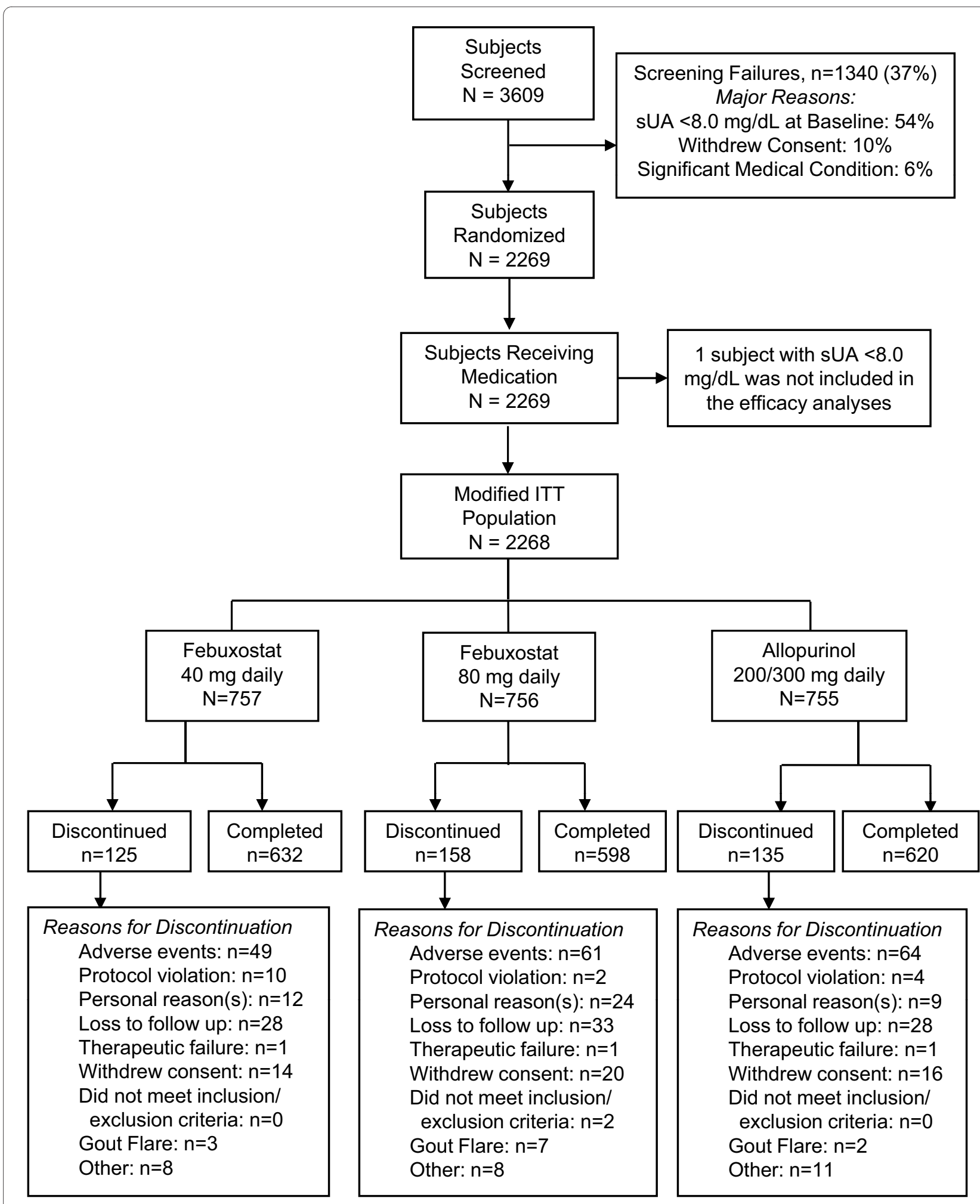

Figure 1 Flow of subjects through the study. One subject randomized to allopurinol was not included in the efficacy analyses because baseline serum urate (sUA) did not meet inclusion criterion. The remaining 2,268 subjects eligible for the study comprised the group in which efficacy was assessed. 
allopurinol treatment group was excluded from the efficacy analyses because baseline sUA was $<8.0 \mathrm{mg} / \mathrm{dL}$. Therefore efficacy analyses are based on the 2,268 subjects in the modified intent-to-treat (mITT) cohort.

\section{Primary efficacy endpoint}

The primary efficacy endpoint was the proportion of subjects in each treatment group with sUA $<6.0 \mathrm{mg} / \mathrm{dL}$ at the final visit. Prior febuxostat RCTs have demonstrated maintenance of efficacy across last three study visits $[34,35]$. A major objective of this study was to evaluate the UL efficacy of febuxostat $40 \mathrm{mg}$; therefore, this treatment group was compared with the allopurinol group with regard to non-inferiority in UL. Binomial 95\% confidence intervals (CIs) were calculated for the difference between the two groups in achieving final sUA $<6.0 \mathrm{mg} /$ dL. Non-inferiority to allopurinol was to be declared for febuxostat $40 \mathrm{mg}$ if the value of the lower limit of the 95\% $\mathrm{CI}$ for the difference in achieving the endpoint was greater than $-10 \%$. If non-inferiority of febuxostat $40 \mathrm{mg}$ was established, superiority to allopurinol was to be assessed using Fisher's exact test (two-tailed, 0.05 significance level). Efficacy comparisons were also to be made comparing febuxostat $80 \mathrm{mg}$ to allopurinol and to febuxostat $40 \mathrm{mg}$, using Fisher's exact test (two-tailed, 0.05 significance level).

\section{Determination of sample size}

A total of 750 subjects per treatment group was required to achieve $90 \%$ power to meet the non-inferiority criteria between febuxostat $40 \mathrm{mg}$ and allopurinol for the primary efficacy variable, and to detect a $10 \%$ difference between febuxostat $40 \mathrm{mg}$ and allopurinol for the primary efficacy variable, and between febuxostat $40 \mathrm{mg}$ and $80 \mathrm{mg}$ for the primary efficacy variable.

\section{Secondary efficacy endpoints}

Secondary efficacy variables included: the proportion of subjects with mild or moderate renal impairment and final sUA $<6.0 \mathrm{mg} / \mathrm{dL}$; and the proportion of subjects with sUA $<6.0 \mathrm{mg} / \mathrm{dL},<5.0 \mathrm{mg} / \mathrm{dL}$, and $<4.0 \mathrm{mg} / \mathrm{dL}$ at each visit. Pairwise comparisons were made between treatment groups with Fisher's exact test.

\section{Subgroup analyses of primary endpoint}

In subgroup analyses, the primary endpoint was stratified by baseline sUA, renal functional status, presence of tophi at baseline, and prior participation in a ULT trial $[13,14]$. A separate logistic regression model was fit for each subgroup factor to assess the association between each subgroup and achievement of the sUA endpoint. Each model included treatment, subgroup, and the interaction between treatment and subgroup as explanatory variables.

\section{Safety analyses}

Safety analyses were carried out on the results from all 2,269 subjects. AEs were summarized using Medical Dic- tionary for Regulatory Activities (MedRA) terminology and reported by count (n) and percentage of subjects reporting any event for that term. Pairwise comparisons between treatment groups were made using Fisher's exact test. As pre-specified, all deaths and AEs considered by investigators to be potentially $\mathrm{CV}$-related were reviewed by a CV Endpoints Committee, composed of three blinded expert adjudicators. The Committee determined if the AE met Antiplatelet Trialists Collaboration (APTC) criteria $[39,40]$ for the following endpoints: $\mathrm{CV}$ death, nonfatal myocardial infarction (MI), and nonfatal stroke. Non-APTC CV events, also adjudicated by the Committee, included unstable angina, coronary revascularization, cerebral revascularization, transient ischemic attack, venous and peripheral arterial vascular thrombotic event, congestive heart failure, and arrhythmia.

\section{Results}

\section{Subject disposition and demographics}

Of the 2,269 subjects randomized, 757, 756, and 756 subjects received at least one daily dose of febuxostat $40 \mathrm{mg}$, febuxostat $80 \mathrm{mg}$, or allopurinol, respectively (Figure 1). Among allopurinol-treated subjects, 610 received $300 \mathrm{mg}$ daily and 145 subjects received an adjusted dose of 200 $\mathrm{mg}$ daily due to moderate renal impairment $(\mathrm{eCLcr}=30$ to $59 \mathrm{ml} /$ minute). In total, 418 subjects prematurely discontinued treatment, 120 within the first month of treatment.

There were no significant differences across treatment groups in demographic, gout-related, or comorbid characteristics of the subjects enrolled (Table 1). As in prior febuxostat/allopurinol comparative trials [34,35], the study groups were composed largely of white ( $82 \%)$, male $(94 \%)$, and obese (BMI $\left.\geq 30 \mathrm{~kg} / \mathrm{m}^{2} ; 64 \%\right)$ persons who acknowledged the use of alcohol (68\%). Of the total cohort, 276 had previously completed a three- to fiveyear open-label ULT trial with either febuxostat or allopurinol [13,14]. These subjects had significantly fewer tophi at baseline compared to those who had not previously participated in either long-term study $(12.5 \%$ vs $22.3 \%$, respectively; $P<0.001$ ); prior participant and nonparticipant groups did not, however, differ significantly in the proportion of subjects with mild or moderate renal impairment (data not shown).

Mild or moderate renal impairment was identified in $65 \%$ of all subjects. Other comorbid conditions included hypertension (53\%), hyperlipidemia (42\%), hypercholesterolemia (7\%), and diabetes (14\%). The majority of subjects $(87 \%)$ reported use of concomitant medications, including medications acting on the renin-angiotensin system (36\%), lipid-modifying agents (31\%), and antiinflammatory and anti-rheumatic products (29\%). Greater than $90 \%$ adherence to treatment was recorded for $80 \%$ of the subjects. 
Table 1: Baseline characteristics of randomized subjects ${ }^{\mathrm{a}}$

\begin{tabular}{|c|c|c|c|}
\hline Variable & $\begin{array}{l}\text { Febuxostat } 40 \text { mg daily } \\
\qquad N=757\end{array}$ & $\begin{array}{c}\text { Febuxostat } 80 \mathrm{mg} \text { daily } \\
\mathrm{N}=756 \\
\mathrm{n}(\%)\end{array}$ & $\begin{array}{c}\text { Allopurinol } 200 / 300 \mathrm{mg} \\
\text { daily } \\
\mathrm{N}=756\end{array}$ \\
\hline \multicolumn{4}{|l|}{ Gender } \\
\hline Male & $722(95.4)$ & $710(93.9)$ & $709(93.8)$ \\
\hline Female & $35(4.6)$ & $46(6.1)$ & $47(6.2)$ \\
\hline \multicolumn{4}{|l|}{ Race } \\
\hline American Indian or Alaska Native & $6(0.8)$ & $10(1.3)$ & $6(0.8)$ \\
\hline Asian & $26(3.4)$ & $25(3.3)$ & $37(4.9)$ \\
\hline Black or African American & $83(11.0)$ & $78(10.3)$ & $67(8.9)$ \\
\hline \multicolumn{4}{|l|}{ Native Hawaiian or Other Pacific } \\
\hline Islander & $11(1.5)$ & $10(1.3)$ & $11(1.5)$ \\
\hline White & $620(81.9)$ & $618(81.7)$ & $625(82.7)$ \\
\hline Other & $11(1.5)$ & $15(2.0)$ & $8(1.1)$ \\
\hline Missing & 0 & 0 & $2(0.3)$ \\
\hline \multicolumn{4}{|l|}{ Ethnicity } \\
\hline Hispanic or Latino & $47(6.2)$ & $49(6.5)$ & $53(7.0)$ \\
\hline Not Hispanic or Latino & $710(93.8)$ & $707(93.5)$ & $702(92.9)$ \\
\hline Missing & 0 & 0 & $1(0.1)$ \\
\hline \multicolumn{4}{|l|}{ Age (years) } \\
\hline Mean \pm SD & $52.5 \pm 11.68$ & $53.0 \pm 11.79$ & $52.9 \pm 11.73$ \\
\hline Range & 21 to 85 & 21 to 85 & 19 to 85 \\
\hline \multicolumn{4}{|l|}{ Body Mass Index (kg/m2) } \\
\hline Mean \pm SD & $32.9 \pm 6.37$ & $32.9 \pm 6.39$ & $32.7 \pm 6.23$ \\
\hline Range & 20 to 64 & 16 to 64 & 17 to 61 \\
\hline \multicolumn{4}{|l|}{ Alcohol Use } \\
\hline Non-/Ex-drinker & $242(32.0)$ & $243(32.1)$ & $235(31.1)$ \\
\hline Drinker (1 to 14 drinks/week) & $515(68.0)$ & $513(67.9)$ & $521(68.9)$ \\
\hline \multicolumn{4}{|l|}{ Serum Urate (mg/dL) } \\
\hline$<9.0$ & $283(37.4)$ & $280(37.0)$ & $274(36.2)$ \\
\hline 9 to $<10.0$ & $225(29.7)$ & $222(29.4)$ & $252(33.3)$ \\
\hline 10.0 to $<11.0$ & $162(21.4)$ & $159(21.0)$ & $133(17.6)$ \\
\hline 11.0 to $<12.0$ & $58(7.7)$ & $67(8.9)$ & $64(8.5)$ \\
\hline$\geq 12.0$ & $29(3.8)$ & $28(3.7)$ & $33(4.4)$ \\
\hline Mean \pm SD & $9.6 \pm 1.15$ & $9.6 \pm 1.20$ & $9.5 \pm 1.19$ \\
\hline Range & 8 to 14 & 8 to 15 & 8 to 15 \\
\hline
\end{tabular}


Table 1: Baseline characteristics of randomized subjects ${ }^{a}$ (Continued)

\begin{tabular}{|c|c|c|c|}
\hline \multicolumn{4}{|l|}{ Years with Gout } \\
\hline Mean \pm SD & $12.0 \pm 9.13$ & $11.7 \pm 9.64$ & $11.2 \pm 9.14$ \\
\hline Range & 0 to 53 & 0 to 51 & 0 to 48 \\
\hline Completed Previous Febuxostat Study & $98(12.9)$ & $88(11.6)$ & $90(11.9)$ \\
\hline \multicolumn{4}{|l|}{ Renal Function ${ }^{b}$} \\
\hline Moderately Impaired & $130(17.2)$ & $136(18.0)$ & $136(18.0)$ \\
\hline Mildly Impaired & $349(46.1)$ & $367(48.5)$ & $365(48.3)$ \\
\hline Normal & $278(36.7)$ & $253(33.5)$ & $255(33.7)$ \\
\hline \multicolumn{4}{|l|}{ Medical History } \\
\hline $\begin{array}{l}\text { Cardiovascular Disease } \\
\text { (including hypertension) }\end{array}$ & $421(55.6)$ & $440(58.2)$ & $436(57.7)$ \\
\hline Diabetes & $89(11.8)$ & $113(14.9)$ & $110(14.6)$ \\
\hline Hypercholesterolemia & $52(6.9)$ & $53(7.0)$ & $57(7.5)$ \\
\hline Hyperlipidemia & $299(39.5)$ & $308(40.7)$ & $335(44.3)$ \\
\hline $\begin{array}{l}\text { Use of Low-dose Aspirin ( } \leq 325 \\
\text { mg daily) }\end{array}$ & $133(17.6)$ & $133(17.6)$ & $139(18.4)$ \\
\hline
\end{tabular}

\section{Efficacy analyses}

\section{Primary efficacy endpoint}

The proportions of subjects achieving a final visit sUA $<6.0 \mathrm{mg} / \mathrm{dL}$, were $45.2 \%, 67.1 \%$, and $42.1 \%$ in the febuxostat $40 \mathrm{mg}$, febuxostat $80 \mathrm{mg}$, and allopurinol groups, respectively. UL by febuxostat $40 \mathrm{mg}$ was non-inferior to that by allopurinol: but the difference in the response rates between the two groups $(3.1 \%, 95 \% \mathrm{CI}:-1.9 \%$ to $8.1 \%)$ was not significant. However, the greater UL response rate with febuxostat $80 \mathrm{mg}$ compared with either febuxostat $40 \mathrm{mg}$ (21.9\%) or allopurinol (24.9\%) was significant $(P<0.001)$.

\section{Secondary efficacy endpoints}

Among subjects with any (mild or moderate) renal impairment, the UL response rate in the febuxostat $80 \mathrm{mg}$ group (71.6\%; 360/503) significantly exceeded those observed in the febuxostat $40 \mathrm{mg}(49.7 \% ; 238 / 479)$ and allopurinol $(42.3 \% ; 212 / 501)$ groups $(P \leq 0.001$, for each comparison). In addition, among the total group of subjects with renal impairment, the UL response rate in the febuxostat $40 \mathrm{mg}$ group was significantly higher than that in the allopurinol $300 / 200 \mathrm{mg}$ group $(P=0.021)$.

At any sUA endpoint $(<6.0 \mathrm{mg} / \mathrm{dL},<5.0 \mathrm{mg} / \mathrm{dL}$, or $<4.0$ $\mathrm{mg} / \mathrm{dL}$ ) and at any scheduled visit, a significantly higher proportion of subjects receiving febuxostat $80 \mathrm{mg}$ achieved the target endpoint than subjects receiving febuxostat $40 \mathrm{mg}$ or allopurinol $(P<0.001)$. Greater proportions of subjects in the febuxostat $40 \mathrm{mg}$ group than the allopurinol group achieved sUA $<6.0 \mathrm{mg} / \mathrm{dL}$ (at Month 2 visit; $P=0.031$ ) and $<5.0 \mathrm{mg} / \mathrm{dL}$ (at two- and sixmonth visits; $P \leq 0.05$ ), but significant differences were not seen at other visits, including the final visit. There were no differences between febuxostat $40 \mathrm{mg}$ and allopurinol groups in achievement of sUA $<4.0 \mathrm{mg} / \mathrm{dL}$.

\section{Subgroup analyses of the primary endpoint}

Among baseline characteristics, higher sUA, presence of tophi, and impaired renal status significantly $(P<0.001)$ and independently affected achievement of the primary endpoint: higher sUA and tophi were associated with lower rates of endpoint achievement, and subjects with mild renal impairment had uniformly higher rates of reaching goal sUA than subjects with normal renal function (Table 2).

Among the 276 subjects who had maintained longterm goal range sUA over three to five years in prior ULT trials $[13,14]$, sUA $<6.0 \mathrm{mg} / \mathrm{dL}$ was achieved at the final visit in $57.1 \%, 77.3 \%$, and $52.2 \%$, respectively, of subjects assigned to the febuxostat $40 \mathrm{mg}$, febuxostat $80 \mathrm{mg}$, and allopurinol groups (Table 2). Achievement of primary endpoint in subjects not previously so treated were, respectively, $43.4 \%, 65.7 \%$, and $40.8 \%$ ( $P \leq 0.05$ for com- 
parison of subjects with and without prior participation for each treatment group).

\section{Gout flares}

Rates of flare requiring treatment occurred in 10\% to $15 \%$ of subjects in all treatment groups during each of the first two months of treatment but declined slowly over the subsequent course of the trial (Figure 2). Of particular note, subjects with prior long-term ULT $[13,14]$ in each treatment group in CONFIRMS had lower rates of flares requiring treatment compared to subjects in the corresponding group without prior participation $(P \leq 0.001$ for each comparison).

\section{Safety Analyses}

\section{Rates of AEs and premature withdrawals}

AEs were reported by $56 \%$ of subjects $(1,272 / 2,269)$. Occurrence rates did not differ among treatment groups (Table 3), nor did rates of most frequently reported AEs. The majority of AEs were mild or moderate in severity.

Rates of AEs in subjects with mild or moderate renal impairment were similar to those in the overall study population: $56 \%$ (268/479), $54 \%(270 / 503)$, and $58 \%$ (289/ 501) of subjects in the febuxostat $40 \mathrm{mg}$, febuxostat 80 $\mathrm{mg}$, and allopurinol groups, respectively, reported at least one $\mathrm{AE}$. The most frequently reported AEs in subjects with renal impairment were the same as those reported for all subjects. Although not significant, rates of abnormal liver function tests were lower among subjects with mild (6\% to $7 \%$ ) or moderate renal impairment (3\% to $6 \%$ ) compared to subjects with normal renal function (9\% to $10 \%)$ in all treatment groups. Rates of diarrhea were higher among subjects with moderate renal impairment receiving febuxostat ( $8 \%$ to $10 \%$ ), compared with subjects with moderate renal impairment receiving allopurinol (7\%).

Most frequently reported serious AEs ( $>0.1 \%$ of all subjects) were non-specific bacterial infections, coronary artery disease, ischemic coronary artery disorders, lower respiratory tract infections, and prostate cancer. Five subjects died during the study: one subject each receiving febuxostat $40 \mathrm{mg}$ (anaphylactic reaction after 50 fire ant stings) and febuxostat $80 \mathrm{mg}$ (brain edema and chronic obstructive pulmonary disease); and three subjects receiving allopurinol (hypertensive heart disease; necrotizing pneumonia and sepsis after surgery for lung adeno-

Table 2: Effect of baseline characteristics on treatment response represented as the percentage of mITT subjects in each subgroup achieving sUA $<6.0 \mathrm{mg} / \mathrm{dL}$ at Final Visit

\begin{tabular}{|c|c|c|c|}
\hline Variable & $\begin{array}{l}\text { Febuxostat } 40 \text { mg daily } \\
\qquad N=757\end{array}$ & $\begin{array}{l}\text { Febuxostat } 80 \text { mg daily } \\
\qquad \begin{array}{c}N=756 \\
\%(n / N)\end{array}\end{array}$ & $\begin{array}{c}\text { Allopurinol } 300 / 200 \mathrm{mg} \\
\text { daily } \\
\mathrm{N}=755\end{array}$ \\
\hline \multicolumn{4}{|l|}{ Renal Function ${ }^{a}$} \\
\hline Moderately Impaired & $43.1(56 / 130)$ & $71.3(97 / 136)$ & $31.6(43 / 136)$ \\
\hline Mildly Impaired & $52.1(182 / 349)$ & $71.7(263 / 367)$ & $46.3(169 / 365)$ \\
\hline Normal & $37.4(104 / 278)$ & $58.1(147 / 253)$ & $41.7(106 / 254)$ \\
\hline \multicolumn{4}{|c|}{ Baseline Serum Urate (mg/dL)a } \\
\hline$<9.0$ & $60.1(170 / 283)$ & $80.4(225 / 280)$ & $52.7(144 / 273)$ \\
\hline 9.0 to $<10.0$ & $47.1(106 / 225)$ & $70.7(157 / 222)$ & $40.5(102 / 252)$ \\
\hline$\geq 10.0$ & $26.5(66 / 249)$ & $49.2(125 / 254)$ & $31.3(72 / 230)$ \\
\hline \multicolumn{4}{|l|}{ Baseline Tophus a } \\
\hline No & $48.1(284 / 591)$ & $69.8(414 / 593)$ & $44.6(271 / 607)$ \\
\hline Yes & $34.9(58 / 166)$ & $57.1(93 / 163)$ & $31.8(47 / 148)$ \\
\hline \multicolumn{4}{|c|}{ Completed Prior Febuxostat Studya } \\
\hline No & $43.4(286 / 659)$ & $65.7(439 / 668)$ & $40.8(271 / 665)$ \\
\hline Yes & $57.1(56 / 98)$ & $77.3(68 / 88)$ & $52.2(47 / 90)$ \\
\hline
\end{tabular}

avariable had a significant $(P<0.001)$ overall effect on attainment of the primary endpoint. After adjusting for the variable, febuxostat $80 \mathrm{mg}$ remained statistically significant compared to both febuxostat $40 \mathrm{mg}$ and allopurinol. 


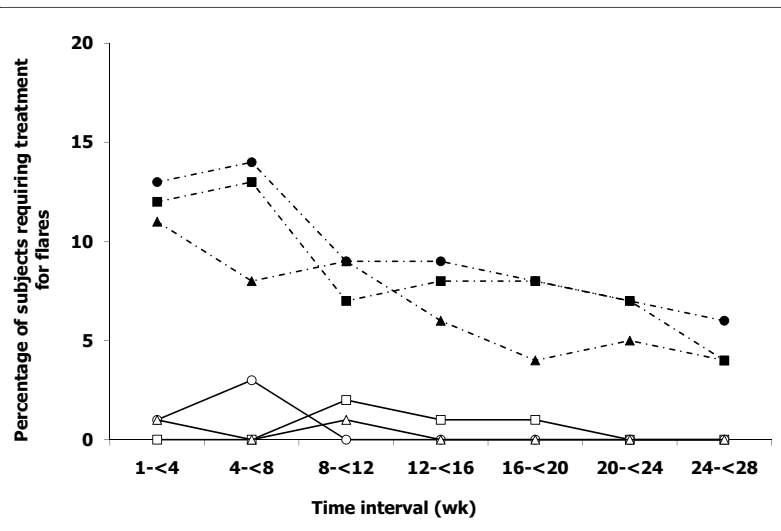

Figure 2 Proportion of subjects requiring gout flare treatment. Solid lines, open symbols, prior participation in long-term open-label ULT extension trials $[13,14]$. Dashed lines and closed symbols, no prior participation in long-term open-label ULT extension trials; squares, febuxostat $40 \mathrm{mg}$ daily; circles, febuxostat $80 \mathrm{mg}$ daily; triangles, allopurinol 200/300 mg daily.

carcinoma; and sudden death). No deaths were judged by investigators to be related to a study drug.

Differences among treatment groups in premature discontinuation rates due to AEs occurring during the study were not significant and are detailed in Figure 1. The most common AEs leading to discontinuation were investigator-defined liver function abnormalities (reported in $2 \%, 1 \%$, and $1 \%$ of subjects receiving febuxostat $40 \mathrm{mg}$, febuxostat $80 \mathrm{mg}$, and allopurinol, respectively).

\section{AEs in specific organ systems}

Rash AEs were reported by $6 \%, 6 \%$, and $7 \%$ of subjects receiving febuxostat $40 \mathrm{mg}$, febuxostat $80 \mathrm{mg}$, and allopurinol, respectively. The most frequently reported rash AEs were dermatitis and eczema (2\%, $2 \%$, and $3 \%$, respectively) and rashes, eruptions, and exanthems (2\%, $2 \%$, and $1 \%$, respectively). With the exception of contact dermatitis, no specific rash was experienced by $>1 \%$ of subjects in any treatment group, and differences in incidence between groups were not significant. Eighteen subjects withdrew prematurely due to a rash $\mathrm{AE}$, including one subject, receiving allopurinol, who had a severe desquamating eruption requiring parenteral corticosteroid therapy.

Rates of liver function abnormalities are shown in Table 3. Aminotransferase elevations were generally mild (not exceeding three-fold the upper limit of normal), transient even with continued study drug treatment, and of similar frequency in febuxostat- and allopurinol-treated subjects. No subjects with combined transaminase increases and serum bilirubin levels exceeding twice the upper limit of normal were observed. Among subjects taking colchicine for flare prophylaxis, the incidence of increased transaminases was similar across treatment groups.

\section{Cardiovascular AEs}

At least one $\mathrm{CV}$ AE was investigator-reported in $5 \%$ of all subjects: $5 \%, 5 \%$, and $6 \%$ of subjects in the febuxostat 40 $\mathrm{mg}$, febuxostat $80 \mathrm{mg}$, and allopurinol groups, respectively. No difference between treatment groups in specific $\mathrm{CV}$ AEs was detected. Pre-specified adjudication of all deaths and all AEs reported to be CV system-related identified a total of six subjects experiencing an adjudicated APTC event: three in the febuxostat $80 \mathrm{mg}$ group and three in the allopurinol group (Table 3 ). All subjects experiencing an adjudicated APTC event had prior medical histories of or underlying risk factors for CVD. Differences in the rates of adjudicated non-APTC CV events between treatment groups were not significant.

\section{Discussion}

In a previous RCT in subjects with gout [33], the UL efficacy of febuxostat at a daily dose of $40 \mathrm{mg}$ was superior to that of placebo. Here, the UL efficacy of febuxostat $40 \mathrm{mg}$ was confirmed as comparable to that of allopurinol 300 $\mathrm{mg}$. At all levels of renal function studied, daily dosing of febuxostat $80 \mathrm{mg}$ was superior in UL efficacy to that of febuxostat $40 \mathrm{mg}$ or allopurinol. However, in subjects with impaired renal function, febuxostat $40 \mathrm{mg}$ was also superior to allopurinol $300 \mathrm{mg}$ daily (mild renal impairment) or $200 \mathrm{mg}$ daily (moderate renal impairment), suggesting that treatment with either dose of febuxostat is more likely to achieve sUA $<6.0 \mathrm{mg} / \mathrm{dL}$ than is allopurinol treatment at the reduced doses widely recommended for such individuals [41]. Indicators of higher body urate pools (baseline presence of tophi or sUA $\geq 10.0 \mathrm{mg} / \mathrm{dL}$ ) were also identified as factors reducing rates of responsiveness to ULT.

If goal range urate levels are not achieved and maintained with febuxostat $40 \mathrm{mg}$ daily or allopurinol, the current data suggest that dose titration to febuxostat $80 \mathrm{mg}$ would be a rational alternative to increasing allopurinol doses beyond $300 \mathrm{mg}$. In fact, RCT evidence to support the safety and efficacy of allopurinol administered at doses exceeding $300 \mathrm{mg}$ daily is limited to a recent fourmonth trial in which 13 of 17 subjects (eCLcr $\geq 50 \mathrm{ml} /$ minute) failing to achieve sUA $<5.0 \mathrm{mg} / \mathrm{dL}$ while receiving allopurinol $300 \mathrm{mg}$ daily safely reached this efficacy endpoint when treated with $600 \mathrm{mg}$ daily [42].

Failure to achieve sUA $<6.0 \mathrm{mg} / \mathrm{dL}$ among individuals with or without renal impairment receiving guidelinerecommended doses of allopurinol has been documented [43]. The common practice of prescribing allopurinol at a fixed daily dose of $300 \mathrm{mg}$ for gout patients with mildly impaired or normal renal function and less for those with moderate renal impairment $[12,18,44]$ may further decrease the likelihood of achieving sUA $<6.0 \mathrm{mg} / \mathrm{dL}$. In this study, there was no titration of allopurinol doses; subjects were assigned the standard daily dose of $300 \mathrm{mg}$ 


\begin{tabular}{|c|c|c|c|}
\hline & $\begin{array}{l}\text { Febuxostat } 40 \mathrm{mg} \text { daily } \\
\qquad \mathrm{N}=757\end{array}$ & $\begin{array}{c}\text { Febuxostat } 80 \mathrm{mg} \text { daily } \\
\mathrm{N}=756 \\
\mathrm{n}(\%)\end{array}$ & $\begin{array}{c}\text { Allopurinol } 200 / 300 \mathrm{mg} \\
\text { daily } \\
\mathrm{N}=756\end{array}$ \\
\hline Total Subjects with $\geq 1 \mathrm{AE}$ & $429(56.7)$ & $410(54.2)$ & $433(57.3)$ \\
\hline $\begin{array}{l}\text { Total Subjects with } \geq 1 \\
\text { Serious AE }\end{array}$ & $19(2.5)$ & $28(3.7)$ & $31(4.1)$ \\
\hline \multicolumn{4}{|l|}{$\begin{array}{l}\text { Most Frequently ( } \geq 5 \% \text { ) } \\
\text { Reported AEs }\end{array}$} \\
\hline $\begin{array}{l}\text { Upper Respiratory Tract } \\
\text { Infections }\end{array}$ & $71(9.4)$ & $53(7.0)$ & $57(7.5)$ \\
\hline Liver Function Analysis & $63(8.3)$ & $52(6.9)$ & $50(6.6)$ \\
\hline Rash & $44(5.8)$ & $42(5.6)$ & $55(7.3)$ \\
\hline Diarrhea & $45(5.9)$ & $47(6.2)$ & $57(7.5)$ \\
\hline $\begin{array}{l}\text { Musculoskeletal and } \\
\text { Connective Tissue Signs } \\
\text { and Symptoms NEC }\end{array}$ & $43(5.7)$ & $38(5.0)$ & $32(4.2)$ \\
\hline \multicolumn{4}{|l|}{ All APTC CV Events } \\
\hline $\begin{array}{l}\text { Number of Subjects with } \\
\text { Events }\end{array}$ & 0 & 3 & 3 \\
\hline Rate (\%) & 0.00 & 0.40 & 0.40 \\
\hline $95 \% \mathrm{Cl}(\%)$ & $(0.000,0.486)$ & $(0.082,1.155)$ & $(0.082,1.155)$ \\
\hline \multicolumn{4}{|c|}{ APTC Events Summarized by Category } \\
\hline CV Death & 0 & 0 & $2(0.26)$ \\
\hline $\begin{array}{l}\text { Nonfatal Myocardial } \\
\text { Infarction }\end{array}$ & 0 & $1(0.13)$ & $1(0.13)$ \\
\hline Nonfatal Stroke & 0 & $2(0.26)$ & 0 \\
\hline \multicolumn{4}{|l|}{ All Non-APTC Events } \\
\hline $\begin{array}{l}\text { Number of Subjects with } \\
\text { Events }\end{array}$ & 10 & 9 & 7 \\
\hline Rate (\%) & 1.32 & 1.19 & 0.93 \\
\hline $95 \%$ Cl (\%) & $(0.635,2.416)$ & $(0.546,2.248)$ & $(0.373,1.898)$ \\
\hline
\end{tabular}

Non-APTC Events Summarized by Category

$\begin{array}{lc}\text { Angina } & 2(0.26) \\ \text { Coronary } & 1(0.13) \\ \text { Revascularization } & \\ \text { Transient Ischemic Attack } & 1(0.13) \\ \text { Cerebral } & 0 \\ \text { Revascularization } & \\ \text { Venous and Peripheral } & 0 \\ \text { Arterial Vascular } & \\ \text { Thrombotic Event } & \\ \text { Congestive Heart Failure } & 2(0.26)\end{array}$

0

0

0

0

$2(0.26)$

0
0

$1(0.13)$

$1(0.13)$

0

0

$1(0.13)$ 
Table 3: Adverse events (Continued)

\begin{tabular}{|c|c|c|c|}
\hline $\begin{array}{l}\text { Arrhythmia, No Evidence } \\
\text { of Ischemia }\end{array}$ & $3(0.40)$ & $4(0.53)$ & $1(0.13)$ \\
\hline $\begin{array}{l}\text { Other Non-APTC CV } \\
\text { Events }\end{array}$ & $1(0.13)$ & $3(0.40)$ & $3(0.40)$ \\
\hline
\end{tabular}

AE: adverse events; APTC: antiplatelet trialists collaboration; Cl: confidence interval; CV: cardiovascular; NEC: not elsewhere characterized

unless they had moderate renal impairment. For this reason and due to the paucity of controlled data cited above [42], we are reluctant to speculate as to whether allopurinol dose escalation would have safely increased the proportion of subjects who achieved target sUA $[42,45]$.

The prior RCTs comparing febuxostat and allopurinol $[34,35]$ did not establish significant differences between these agents in the clinical outcomes of flare rate and tophus size reductions in the first 6 to 12 months of treatment. As such, clinical outcomes were not endpoints in the current trial. Nevertheless, subjects who had successfully completed prior the long-term open-label UL studies $[13,14]$ and then enrolled in CONFIRMS had reduced rates of baseline tophi and, during the additional six months of ULT, showed higher rates of UL efficacy and reduced rates of gout flares compared with those who did not have prior trial participation. These data support the concept that persistent UL to sub-saturating sUA eventually results in relief of clinical symptoms of both acute (flares) and chronic (tophi) gout $[8,10,12]$ likely by depletion of excessive miscible and non-miscible (crystalline) extracellular urate pools characteristic of gout patients $[46,47]$.

In all treatment groups, rates of gout flares requiring treatment diminished slowly after Month 2 and did not affect more than $15 \%$ of subjects per month after Week 8 of the study (Figure 2). This result contrasts with sharp increases in flare rates $(30 \%$ to $40 \%$ of subjects per month) encountered after cessation of flare prophylaxis at Month 2 in prior comparative RCTs [34,35]. These results seem likely due to differences in the duration of prophylaxis and are in accord with the results of an RCT that established the efficacy of colchicine flare prophylaxis during the first six months after initiation of allopurinol therapy [48]. We thus recommend gout flare prophylaxis co-therapy for at least the first six months of ULT.

As in prior febuxostat clinical trials [13,14,33-35], no severe rashes or hypersensitivity reactions were observed during febuxostat treatment in the current trial. In these trials, serum transaminase elevations ( $\geq$ three times upper limit of normal) were numerically more frequent with febuxostat than with allopurinol, but neither concurrent serum bilirubin levels exceeding $2 \mathrm{mg} / \mathrm{dL}$ nor clinicallymanifested liver-related symptoms were encountered
$[34,35]$. In the entire febuxostat development program [13,14,33-35], neither febuxostat nor allopurinol treatment was associated with combined serum transaminase and bilirubin increases, except when explained by cholecystitis or by bile duct obstruction due to stones or malignancy. Nevertheless, administration of allopurinol or febuxostat to a gout population with significant rates of obesity, metabolic syndrome, and alcohol use [34,35] is accompanied by liver function test abnormalities more frequently than is placebo administration [35]. Consequently, we recommend periodic liver function testing during treatment with either febuxostat or allopurinol.

A lack of significant differences in overall rates of AEs or of the most frequently occurring treatment emergent AEs across febuxostat and allopurinol treatment groups in CONFIRMS recapitulate safety results previously reported $[34,35]$. In addition, in this study encompassing a greater number of subjects than all prior febuxostat/ allopurinol RCTs combined, no significant differences between treatment groups were observed in the rates of reported CV AEs, adjudicated APTC, or non-APTC events. Gout and hyperuricemia are strongly associated with CVD and CVD-related death [24-29,49], and all subjects who experienced adjudicated CV events had prior medical histories or risk factors for CVD. Thus, despite the fact that the small number of severe CV AEs encountered in febuxostat/allopurinol comparative RCTs did not identify a differential CV risk of these agents, we recommend continued attention to monitoring and management of CV health, particularly among gout patients at high risk for CV events.

\section{Conclusions}

Results of the CONFIRMS trial establish equivalent UL efficacy for febuxostat $40 \mathrm{mg}$ daily and allopurinol 300/ $200 \mathrm{mg}$ daily. At all levels of renal function studied, UL efficacy of febuxostat $80 \mathrm{mg}$ daily was superior to that of febuxostat $40 \mathrm{mg}$ or allopurinol $300 / 200 \mathrm{mg}$, and was comparably safe. In subjects with mildly or moderately impaired renal function, however, febuxostat $40 \mathrm{mg}$ daily was significantly more effective in lowering sUA than allopurinol. At the doses studied, safety of febuxostat and allopurinol, including CV safety, was comparable. Febuxostat, at $40 \mathrm{mg}$ or $80 \mathrm{mg}$ daily, offers a well-tolerated UL alternative to allopurinol, particularly for patients with mild or moderate renal impairment. 


\section{Abbreviations}

AE: adverse event; APTC: Antiplatelet Trialists Collaboration; BMI: body mass index; Cl: confidence interval; CV: cardiovascular; CVD: cardiovascular disease: eCLcr: estimated creatinine clearance; MI: myocardial infection; mITT: modified intent-to-treat; RCT: randomized controlled trial; sUA: serum urate; UL: urate lowering; ULT: urate-lowering therapy; XO: xanthine oxidase.

\section{Competing interests}

MAB has served as a consultant for Takeda Global Research \& Development Center, Inc. and Savient Pharmaceuticals $(>\$ 10,000)$ and for Biocryst Pharmaceuticals, Regeneron Pharmaceuticals, Proctor \& Gamble, Inc., and URL Pharma $(<\$ 10,000)$. LRE has received consulting fees from Takeda Global Research \& Development Center, Inc. $(<\$ 10,000)$. HRS has received consulting fees $(<\$ 10,000)$ from Takeda Global Research \& Development Center, Inc., Savient Pharmaceuticals, Regeneron Pharmaceuticals, Pfizer, Inc., Xoma, Centocor, Inc., and has received research grants from Takeda Global Research \& Development Center, Inc., CherryPharm, and Wyeth Pharmaceuticals (now a part of Pfizer, Inc.). AFW has served as a consultant for Takeda Global Research \& Development Center, Inc.(> $\$ 10,000)$, Abbott Laboratories, Amgen, Inc., Bristol-Myers Squibb Company, Centocor, Inc., Eli Lilly and Company, GlaxoSmithKline, Pfizer, Inc., Wyeth Pharmaceuticals, and Genetech, Inc. (all <\$10,000). PM and EL are currently employees of Takeda Global Research \& Development Center, Inc. Deerfield, IL, USA. They were employees of TAP Pharmaceutical Products Inc. at the time of the study conduct and analysis. CL was an employee of TAP Pharmaceutical Products Inc. at the time of the study conduct and analysis.

\section{Authors' contributions}

MAB and PM made substantial contributions to the conception and design of the study; acquisition, analysis and interpretation of the data; drafting and revising of the manuscript; and gave final approval for publication. HRS participated in the analysis and interpretation of the data; drafting and revising of the manuscript; and gave final approval for publication. LRE and AFW were involved in drafting and revising the manuscript; and gave final approval for publication. EL and CL contributed to the conception and design of the study analysis and interpretation of the data; drafting and revising of the manuscript; and gave final approval for publication.

\section{Acknowledgements}

This trial was completely funded by TAP Pharmaceutical Products, Inc., which is now a part of Takeda Global Research \& Development Center, Inc., Deerfield, IL, USA. It is registered as NCT00430248 on clinicaltrials.gov. The authors would like to thank Nancy Joseph-Ridge, MD, Global Head of Development, General Manager, Pharmaceutical Development Division, Takeda Pharmaceuticals International, Inc. and Barbara Hunt, Associate Director, Statistics, Takeda Global Research \& Development Center, Inc. for their critical review of the manuscript. Assistance in manuscript preparation was provided by Meryl Gersh, PhD, of AlphaBioCom, LLC, in Radnor, PA, USA, and was funded by Takeda Global Research \& Development Center, Inc.

\section{Author Details}

1The University of Chicago Pritzker School of Medicine, MC0930, University of Chicago Medical Center, 5841 S. Maryland Avenue, Chicago, IL 60637, USA, 2University of Pennsylvania and VA Medical Center, VA Medical Center, 151K University and Woodland Avenues, Philadelphia, PA 19104, USA,

${ }^{3}$ Rheumatology, Louisiana State University Health Sciences Center, 2820 Napoleon Avenue, Suite 890, New Orleans, LA 70115, USA, 4Rosalind Franklin University of Medicine \& Science, 1457 Indian Grass Lane, Grays Lake, IL 60030, USA, ${ }^{5}$ Takeda Global Research \& Development Center Inc., One Takeda Parkway, Deerfield, IL 60015, USA and ${ }^{6}$ Astellas Pharma Global Development Inc., 3 Parkway North, Deerfield, IL 60015, USA

\section{Received: 29 October 2009 Revised: 2 February 2010}

Accepted: 6 April 2010 Published: 6 April 2010

\section{References}

1. Arromdee E, Michet CJ, Crowson CS, O'Fallon WM, Gabriel SE: Epidemiology of gout: is the incidence rising? J Rheumato/ 2002, 29:2403-2406.

2. Choi H: Epidemiology of crystal arthropathy. Rheum Dis Clin North Am 2006, 32:255-273.

3. Roddy E, Zhang W, Doherty M: The changing epidemiology of gout. Nat Clin Pract Rheumatol 2007, 3:443-449.
4. Lawrence RC, Felson DT, Helmick CG, Arnold LM, Choi H, Deyo RA, Gabriel S, Hirsch R, Hochberg MC, Hunder GG, Jordan JM, Katz JN, Kremers HM, Wolfe F: Estimates of the prevalence of arthritis and other rheumatic conditions in the United States. Part II. Arthritis Rheum 2008, 58:26-35.

5. Wallace KL, Riedel AA, Joseph-Ridge N, Wortmann R: Increasing prevalence of gout and hyperuricemia over 10 years among older adults in a managed care population. J Rheumatol 2004, 31:1582-1587.

6. Terkeltaub RA: Clinical practice. Gout. N Eng/ J Med 2003, 349:1647-1655.

7. Becker MA, Chohan S: We can make gout management more successful now. Curr Opin Rheumatol 2008, 20:167-172.

8. Li-Yu J, Clayburne G, Sieck M, Beutler A, Rull M, Eisner E, Schumacher HR Jr: Treatment of chronic gout. Can we determine when urate stores are depleted enough to prevent attacks of gout? J Rheumatol 2001, 28:577-580.

9. Perez-Ruiz F, Calabozo M, Pijoan Jl, Herrero-Beites AM, Ruibal A: Effect of urate-lowering therapy on the velocity of size reduction of tophi in chronic gout. Arthritis Rheum 2002, 47:356-360.

10. Perez-Ruiz F, Liote F: Lowering serum uric acid levels: what is the optimal target for improving clinical outcomes in gout? Arthritis Rheum 2007, 57:1324-1328.

11. Shoji A, Yamanaka H, Kamatani N: A retrospective study of the relationship between serum urate level and recurrent attacks of gouty arthritis: evidence for reduction of recurrent gouty arthritis with antihyperuricemic therapy. Arthritis Rheum 2004, 51:321-325.

12. Zhang W, Doherty M, Bardin T, Pascual E, Barskova V, Conaghan P, Gerster J, Jacobs J, Leeb B, Liote F, McCarthy G, Netter P, Nuki G, Perez-Ruiz F, Pignone A, Pimentao J, Punzi L, Roddy E, Uhlig T, Zimmermann-Gorska l: EULAR evidence based recommendations for gout. Part II: Management. Report of a task force of the EULAR Standing Committee for International Clinical Studies Including Therapeutics (ESCISIT). Ann Rheum Dis 2006, 65:1312-1324.

13. Schumacher HR Jr, Becker MA, Lloyd E, MacDonald PA, Lademacher C: Febuxostat in the treatment of gout: 5 -yr findings of the FOCUS efficacy and safety study. Rheumatology (Oxford) 2009, 48:188-194.

14. Becker MA, Schumacher HR, MacDonald PA, Lloyd E, Lademacher C: Clinical efficacy and safety of successful long-term urate lowering with febuxostat or allopurinol in subjects with gout. J Rheumatol 2009, 36:1273-1278

15. Allopurinol U.S. Prescribing Information. Apotex Corp., Weston, FL; 2006.

16. Sarawate CA, Brewer KK, Yang W, Patel PA, Schumacher HR, Saag KG, Bakst AW: Gout medication treatment patterns and adherence to standards of care from a managed care perspective. Mayo Clin Proc 2006, 81:925-934.

17. Perez-Ruiz F, Alonso-Ruiz A, Calabozo M, Herrero-Beites A, Garcia-Erauskin $G$, Ruiz-Lucea E: Efficacy of allopurinol and benzbromarone for the control of hyperuricaemia. A pathogenic approach to the treatment of primary chronic gout. Ann Rheum Dis 1998, 57:545-549.

18. Sarawate CA, Patel PA, Schumacher HR, Yang W, Brewer KK, Bakst AW: Serum urate levels and gout flares: analysis from managed care data. J Clin Rheumatol 2006, 12:61-65.

19. Becker MA, Schumacher HR, Benjamin KL, Gorevic P, Greenwald M, Fessel J, Edwards L, Kawata AK, Frank L, Waltrip R, Maroli A, Huang B, Sundy JS: Quality of life and disability in patients with treatment-failure gout. $J$ Rheumatol 2009, 36:1041-1048.

20. Edwards NL: Treatment-failure gout: A moving target. Arthritis Rheum 2008, 58:2587-2590.

21. Lee SJ, Hirsch JD, Terkeltaub R, Khanna D, Singh JA, Sarkin A, Kavanaugh A: Perceptions of disease and health-related quality of life among patients with gout. Rheumatology (Oxford) 2009, 48:582-586.

22. Becker MA, Jolly M: Hyperuricemia and associated diseases. Rheum Dis Clin North Am 2006, 32:275-293.

23. Baker JF, Krishnan E, Chen L, Schumacher HR: Serum uric acid and cardiovascular disease: recent developments, and where do they leave us? Am J Med 2005, 118:816-826.

24. Abbott RD, Brand FN, Kannel WB, Castelli WP: Gout and coronary heart disease: the Framingham Study. J Clin Epidemiol 1988, 41:237-242.

25. Culleton BF, Larson MG, Kannel WB, Levy D: Serum uric acid and risk for cardiovascular disease and death: the Framingham Heart Study. Ann Intern Med 1999, 131:7-13.

26. Fang J, Alderman MH: Serum uric acid and cardiovascular mortality the NHANES I epidemiologic follow-up study, 1971-1992. National Health and Nutrition Examination Survey. JAMA 2000, 283:2404-2410. 
27. loachimescu AG, Brennan DM, Hoar BM, Hazen SL, Hoogwerf BJ: Serum uric acid is an independent predictor of all-cause mortality in patients at high risk of cardiovascular disease: a preventive cardiology information system (PreCIS) database cohort study. Arthritis Rheum 2008, 58:623-630

28. Krishnan E, Svendsen K, Neaton JD, Grandits G, Kuller LH: Long-term cardiovascular mortality among middle-aged men with gout. Arch Intern Med 2008, 168:1104-1110.

29. Hak AE, Choi HK: Lifestyle and gout. Curr Opin Rheumatol 2008, 20:179-186

30. Puig JG, Martinez MA: Hyperuricemia, gout and the metabolic syndrome. Curr Opin Rheumatol 2008, 20:187-191.

31. Takano Y, Hase-Aoki K, Horiuchi H, Zhao L, Kasahara Y, Kondo S, Becker MA: Selectivity of febuxostat, a novel non-purine inhibitor of xanthine oxidase/xanthine dehydrogenase. Life Sci 2005, 76:1835-1847.

32. Uloric ${ }^{\circ}$ Full Prescribing Information. Takeda Pharmaceuticals North America, Inc., Deerfield, IL; 2009.

33. Becker MA, Schumacher HR Jr, Wortmann RL, MacDonald PA, Palo WA, Eustace D, Vernillet L, Joseph-Ridge N: Febuxostat, a novel nonpurine selective inhibitor of xanthine oxidase: a twenty-eight-day, multicenter, phase II, randomized, double-blind, placebo-controlled, dose-response clinical trial examining safety and efficacy in patients with gout. Arthritis Rheum 2005, 52:916-923.

34. Becker MA, Schumacher HR Jr, Wortmann RL, MacDonald PA, Eustace D, Palo WA, Streit J, Joseph-Ridge N: Febuxostat compared with allopurinol in patients with hyperuricemia and gout. N Engl J Med 2005 353:2450-2461.

35. Schumacher HR Jr, Becker MA, Wortmann RL, Macdonald PA, Hunt B, Streit J, Lademacher C, Joseph-Ridge N: Effects of febuxostat versus allopurinol and placebo in reducing serum urate in subjects with hyperuricemia and gout: a 28-week, phase III, randomized, doubleblind, parallel-group trial. Arthritis Rheum 2008, 59:1540-1548.

36. Wallace SL, Robinson H, Masi AT, Decker JL, McCarty DJ, Yu TF: Preliminary criteria for the classification of the acute arthritis of primary gout. Arthritis Rheum 1977, 20:895-900.

37. Cockcroft DW, Gault MH: Prediction of creatinine clearance from serum creatinine. Nephron 1976, 16:31-41.

38. Robert S, Zarowitz BJ, Peterson EL, Dumler F: Predictability of creatinine clearance estimates in critically ill patients. Crit Care Med 1993, 21:1487-1495.

39. Collaborative overview of randomised trials of antiplatelet therapy--I: Prevention of death, myocardial infarction, and stroke by prolonged antiplatelet therapy in various categories of patients. Antiplatelet Trialists' Collaboration. BMJ 1994, 308:81-106.

40. White WB, Faich G, Borer JS, Makuch RW: Cardiovascular thrombotic events in arthritis trials of the cyclooxygenase-2 inhibitor celecoxib. Am J Cardiol 2003, 92:411-418.

41. Hande KR, Noone RM, Stone WJ: Severe allopurinol toxicity. Description and guidelines for prevention in patients with renal insufficiency. Am J Med 1984, 76:47-56

42. Reinders MK, Haagsma C, Jansen TL, van Roon EN, Delsing J, Laar MA van de, Brouwers JR: A randomised controlled trial on the efficacy and tolerability with dose-escalation of allopurinol $300-600 \mathrm{mg} /$ day versus benzbromarone $100-200 \mathrm{mg} /$ day in patients with gout. Ann Rheum Dis 2009, 68:892-897.

43. Dalbeth N, Kumar S, Stamp L, Gow P: Dose adjustment of allopurinol according to creatinine clearance does not provide adequate control of hyperuricemia in patients with gout. J Rheumatol 2006, 33:1646-1650

44. Dalbeth N, Stamp L: Allopurinol dosing in renal impairment: walking the tightrope between adequate urate lowering and adverse events. Semin Dial 2007, 20:391-395.

45. Chung Y, Stocker SL, Graham GG, Day RO: Optimizing therapy with allopurinol: factors limiting hypouricemic efficacy. Am J Med Sci 2008, 335:219-226.

46. Pascual E, Batlle-Gualda E, Martinez A, Rosas J, Vela P: Synovial fluid analysis for diagnosis of intercritical gout. Ann Intern Med 1999, 131:756-759.

47. Schumacher HR: Crystal-induced arthritis: an overview. Am J Med 1996, 100:46S-52S.
48. Borstad GC, Bryant LR, Abel MP, Scroggie DA, Harris MD, Alloway JA: Colchicine for prophylaxis of acute flares when initiating allopurinol for chronic gouty arthritis. J Rheumatol 2004, 31:2429-2432.

49. Choi HK, Curhan G: Independent impact of gout on mortality and risk for coronary heart disease. Circulation 2007, 116:894-900.

doi: $10.1186 /$ ar2978

Cite this article as: Becker et al, The urate-lowering efficacy and safety of febuxostat in the treatment of the hyperuricemia of gout: the CONFIRMS trial Arthritis Research \& Therapy 2010, 12:R63

\section{Submit your next manuscript to BioMed Central} and take full advantage of:

- Convenient online submission

- Thorough peer review

- No space constraints or color figure charges

- Immediate publication on acceptance

- Inclusion in PubMed, CAS, Scopus and Google Scholar

- Research which is freely available for redistribution 